American Journal of Applied Sciences 7 (7): 1026-1031, 2010

ISSN 1546-9239

(C) 2010 Science Publications

\title{
Fuzzy Deduction Material Removal Rate Optimization for Computer Numerical Control Turning
}

\author{
Tian-Syung Lan \\ Department of Information Management, Yu Da University, \\ Miaoli County, Taiwan 361, ROC
}

\begin{abstract}
Problem statement: Material Removal Rate (MRR) is often a major consideration in the modern Computer Numerical Control (CNC) turning industry. Most existing optimization researches for $\mathrm{CNC}$ finish turning were either accomplished within certain manufacturing circumstances, or achieved through numerous equipment operations. Therefore, a general deduction optimization scheme is deemed to be necessary proposed for the industry. Approach: In this study, four parameters (cutting depth, feed rate, speed, tool nose runoff) with three levels (low, medium, high) were considered to optimize the MRR in finish turning based on $\mathrm{L}_{9}\left(3^{4}\right)$ orthogonal array. Additionally, nine fuzzy control rules using triangle membership function with respective to five linguistic grades for the MRR is constructed. Considering four input and twenty output intervals, the defuzzification using center of gravity was thus completed for the Taguchi experiment. Therefore, the optimum general deduction parameters can then be received. Results: The confirmation experiment for optimum general deduction parameters was furthermore performed on an ECOCA-3807 CNC lathe. It was shown that the material removal rates from the fuzzy Taguchi deduction optimization parameters are all significantly advanced comparing to those from the benchmark. Conclusion: This study not only proposed a general deduction optimization scheme using orthogonal array, but also contributed the satisfactory fuzzy linguistic approach for the MRR in CNC turning with profound insight.
\end{abstract}

Key words: Computer numerical control, material removal rate, orthogonal array, fuzzy deduction

\section{INTRODUCTION}

Machining operations have been the core of the manufacturing industry since the industrial revolution (Venkata, 2006). The existing optimization researches for $\mathrm{CNC}$ (computer numerical controlled) turning were either simulated within particular manufacturing circumstances (Davim and Conceicao Antonio, 2001; Lin et al., 2001; Lin, 1998; Meng et al., 2000), or achieved through numerous frequent equipment operations (Kopa, 2002; Tosun and Ozler, 2004). Nevertheless, these are regarded as computing simulations and the applicability to real world industry is still uncertain. Therefore, a general deduction optimization scheme without equipment operations is deemed to be necessarily developed.

Surface roughness, tool life and cutting force are commonly considered as manufacturing goals (Davim and Conceicao Antonio, 2001) for turning operations in many of the existing researches. Since the productivity concern becomes more critical in the industry, this study proposes Material Removal Rate (MRR) as the major consideration instead. The machining process on a CNC lathe is programmed by speed, feed rate and cutting depth, which are frequently determined based on the job shop experiences. However, the machine performance and the product characteristics are not guaranteed to be acceptable. Therefore, the optimum turning conditions have to be accomplished. It is mentioned that the tool nose run-off will affect the performance of the machining process (Jianliang and Rongdi, 2006). Therefore, the tool nose run-off is also selected as one of the control factors in this study.

Parameter optimization is a hard-solving issue because of the interactions between parameters. Problems related to the enhancement of product quality and production efficiency can always be related to the optimization procedures. Taguchi method, an experimental design method, has been widely applied to many industries. It can not only optimize quality characteristics through the setting of design parameters, but also reduce the sensitivity of the system performance to sources of variation (Huh et al., 2003; Anastasiou, 2002; Dhavlikar et al., 2003; Kim et al., 2003). The Taguchi method adopts a set of orthogonal arrays to investigate the effect of parameters on specific quality characteristics to decide the optimum parameter combination. These kinds of arrays use a small number 
of experimental runs to analyze the quality effects of parameters as well as the optimum combination of parameters.

To achieve the general optimization, it is necessary to first describe the dynamic behavior of the system to be controlled. Because of the number, complexity and unclear, vague nature of the variables of the dynamic systems that may influence the decision maker's decision, fuzzy set theory is the most suitable solution (Zadeh, 1965; Edgar et al., 2008). Fuzzy linguistic models permit the translation of verbal expressions into numerical ones (Gungor and Arikan, 2007). Therefore, the input output relationship of the process can be described by the collection of fuzzy control rules involving linguistic variables rather than a complicated dynamic mathematical model.

With all the viewpoints above, this study considers four parameters (cutting depth, feed rate, speed, tool nose runoff) with three levels (low, medium, high) to optimize the material removal rate in CNC turning. The fuzzy control rules using triangle membership function with respective to five linguistic grades for the material removal rate are additionally constructed. The defuzzification is then quantified using center of gravity and then introduced to Taguchi experiment. Thus, the optimum general deduction parameters can then be received. This study definitely proposes a fuzzy deduction general optimization approach and satisfactory fuzzy linguistic technique for improving the MRR in CNC turning with profound insight.

\section{MATERIALS AND METHODS}

In this study, the linguistic variable quantification and parameter optimization for general deduction $\mathrm{CNC}$ turning operations are proposed using fuzzy set theory and Taguchi method respectively. They are described as below.

Fuzzy set theory: Let $X$ be an universe of discourse, $\tilde{A}$ is a fuzzy subset of $X$ if for all $x \in X$, there is a number $\mu_{\tilde{A}}(x) \in[0,1]$ assigned to represent the membership of $x-\tilde{A}$ and $\mu_{\tilde{A}}(x)$ is called the membership function of $\tilde{A}$. A triangular fuzzy number $\tilde{A}$ can be defined by a trip-let (a, b, c) (Fig. 1) (Haag et al., 2010). The membership function is defined as:

$$
\mu_{\tilde{A}}(x: a, b, c)= \begin{cases}\frac{x-a}{b-c} & a<x \leq b \\ \frac{x-b}{c-b} & b<x \leq c \\ 0 & \text { otherwise }\end{cases}
$$

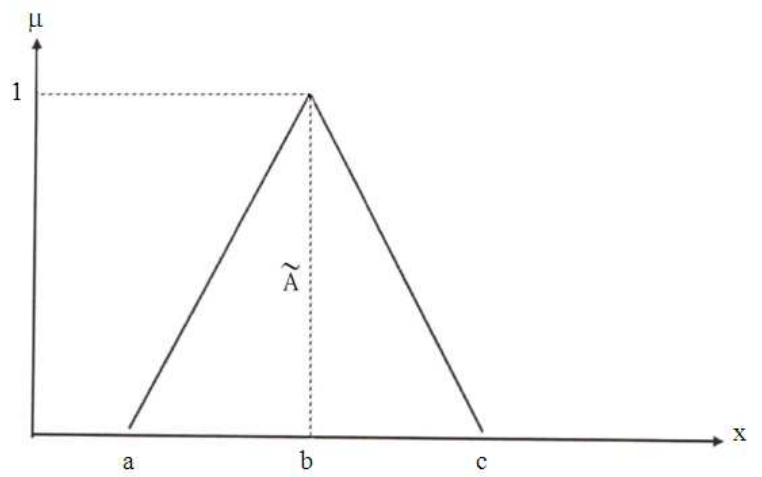

Fig. 1: A triangle fuzzy numbers

In this study, the two most important parameters for MRR are primarily concluded through literature review. Additionally, nine fuzzy control rules for MRR using triangle membership function with respective to five linguistic grades will be constructed following IFTHEN rules.

To eliminate the computation, four input (parameter) and twenty output (quality) intervals are considered to prepare the defuzzification. Through Cartesian product, the degree of membership for both input and output can thus be attained as:

$\mathrm{R}=$ Input $*$ Output

Here:

Input $=$ The parameter

Output $=$ The quality

$\mathrm{R} \quad=$ The fuzzy relation between the parameter and quality

The "OR" rules are then utilized for combining rules for maximum degree of membership as:

$\mu \mathrm{R} 1+\mu \mathrm{R} 2=\max \{\mu \mathrm{R} 1, \mu \mathrm{R} 2\}$

where, R1 and R2 symbolize for the two rules.

In this study, the average value using center of gravity is determined to represent the fuzzy set as:

$\mathrm{F}\left(\mathrm{x}_{\mathrm{i}}\right)=\frac{\sum_{\mathrm{i}} \mathrm{x}_{\mathrm{i}} * \mu_{\tilde{\mathrm{A}}}\left(\mathrm{x}_{\mathrm{i}}\right)}{\sum_{\mathrm{i}} \mu_{\tilde{\mathrm{A}}}\left(\mathrm{x}_{\mathrm{i}}\right)}$

Where:

$\mathrm{F}\left(\mathrm{x}_{\mathrm{i}}\right) \quad=$ The final rating of activity

$\mu_{\tilde{A}}\left(x_{i}\right)=$ The membership function of fuzzy set $\tilde{A}$ 
Taguchi method: The Taguchi method is a robust design method technique (Palanikumar, 2008; Ross, 1995), which provides a simple way to design an efficient and cost effective experiment. In order to efficiently reduce the numbers of conventional experimental tasks, the orthogonal array (Wang and Huang, 2007; Chiang and Hsieh, 2009) by using design parameters (control factors) in column and standard quantities (levels) in row is proposed and further adopted. The performance measure, Signal-to-Noise ratio (S/N) (Park et al., 2005) proposed by Taguchi is used to obtain the optimal parameter combinations. The larger $\mathrm{S} / \mathrm{N}$ means the relation to the quality will become better. The lower quality characteristic will be regarded as a better result when considering the smaller-the-best quality. The related $\mathrm{S} / \mathrm{N}$ ratio is defined as:

$\mathrm{S} / \mathrm{N}=-10\left(\log \sum_{\mathrm{i}=1}^{\mathrm{n}} \frac{\mathrm{y}_{\mathrm{i}}^{2}}{\mathrm{n}}\right)(\mathrm{db})$

Where:

$\mathrm{n}=$ The number of experiments for each experimental set

$y_{i}=$ Expresses the quality characteristic at the i-th experiment

On the contrary, the larger quality characteristic will have better result $t$ when considering the larger-thebest quality, therefore, by taking the inverse of quality characteristic into Eq. 5, the related $\mathrm{S} / \mathrm{N}$ ratio can also be deduced and shown in Eq. 6:

$\mathrm{S} / \mathrm{N}=-10\left(\log \sum_{\mathrm{i}=1}^{\mathrm{n}} \frac{1 / \mathrm{y}_{\mathrm{i}}^{2}}{\mathrm{n}}\right)(\mathrm{dB})$

In this study, the quantified fuzzy result is introduced to the Taguchi experiment as the $\mathrm{S} / \mathrm{N}$ ratio. Therefore, it is judged as the quality of larger-the-best. In addition to the $\mathrm{S} / \mathrm{N}$ ratio, a statistical Analysis Of Variance (ANOVA) (Wu and Chyu, 2002) can be employed to indicate the impact of process parameters. In this way, the optimal levels of process parameters can be estimated.

Research design: Material Removal Rate (MRR) is considered the major quality in this study. Four parameters with three levels are selected to optimize the MRR in finish turning based on the $\mathrm{L}_{9}\left(3^{4}\right)$ orthogonal array. Additionally, nine fuzzy control rules with respective to five linguistic grades for the MRR are constructed. Considering four input and twenty output intervals, the defuzzification using center of gravity is thus completed for the Taguchi experiment and thus the optimum general deduction parameters can then be received.

Construction of orthogonal array: In this study, the four turning parameters (A-speed, B-cutting depth, Cfeed rate and D-tool nose runoff D) (Lan and Wang, 2009) with three different levels (low, medium and high) (Table 1) are constructed for the deduction optimization of machining operation. The orthogonal array is then selected to perform the nine sets of deduction experiments.

Fuzzy control rules: The nine fuzzy control rules with respective to five linguistic grades for material removal rate in this study are constructed. The material removal rate can be expressed as $\mathrm{MRR}=1000 \mathrm{fdV}$. As the experimental results (Davim and Conceicao Antonio, 2001), the surface speed (V) has the least effect to the MRR. Therefore, the depth of cut (d) and feed rate (f) are considered major parameters for MRR. The five linguistic grades for tool wear are determined as excellent (huge), good (large), fair, poor (light) and worse (least). The fuzzy rules can be described as:

Rule 1: If low depth of cut and low feed rate, then the MRR is worst

Rule 2: If medium depth of cut and medium feed rate, then the MRR is fair

Rule 3: If high depth of cut and high feed rate, then the MRR is excellent

Rule 4: If low depth of cut and medium feed rate, then the MRR is poor

Rule 5: If medium depth of cut and high feed rate, then the MRR is good

Rule 6: If high depth of cut and low feed rate, then the MRR is fair

Rule 7: If low depth of cut and high feed rate, then the MRR is fair

Rule 8: If medium depth of cut and low feed rate, then the MRR is poor

Rule 9: If high depth of cut and medium feed rate, then the MRR is good

Table 1: Orthogonal array

\begin{tabular}{lllll}
\hline & Parameter & & \\
& - & & \\
Experiment & (speed) & B & (cutting depth) & C \\
(feed rate) & $\begin{array}{l}\text { D (tool } \\
\text { nose runoff) }\end{array}$ \\
\hline 1 & Low & Low & Low & Low \\
2 & Low & Medium & Medium & Medium \\
3 & Low & High & High & High \\
4 & Medium & Low & Medium & High \\
5 & Medium & Medium & High & Low \\
6 & Medium & High & Low & Medium \\
7 & High & Low & High & Medium \\
8 & High & Medium & Low & High \\
9 & High & High & Medium & Low \\
\hline
\end{tabular}




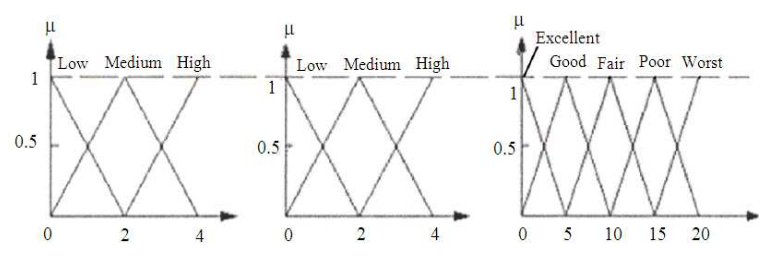

Fig. 2: Relationship of membership functions

Table 2: Degree of membership for parameter

\begin{tabular}{llllll}
\hline & \multicolumn{3}{l}{ Interval } & & \\
Fuzzy item & 0 & 1 & 2 & 3 & 4 \\
\hline Low & 1 & 0.5 & 0 & 0.0 & 0 \\
Medium & 0 & 0.5 & 1 & 0.5 & 0 \\
High & 0 & 0.0 & 0 & 0.5 & 1 \\
\hline
\end{tabular}

Defuzzification: In this study, the three parameter levels are selected based on the Taguchi experimental method, therefore, each triangle membership function is related to the peak point of its fuzzy area. Considering four input and twenty output intervals, the defuzzification of five linguistic grades using center of gravity can then be completed.

Since two major parameters are considered for the quality, the input (parameter) membership functions are regard as the intersection of two fuzzy sets and the height of fuzzy set is considered as $\mu=1$ (Fig. 2). The degree of membership for input (parameter) and output (quality) can be described as shown in Table 2 and Table 3 respectively. Utilizing the average value of the fuzzy set to represent the entire set, we then have the quantified result for the fuzzy item of five linguistic grades as shown in Table 4.

\section{RESULTS}

By considering the parameter combinations of the nine sets of experiment based on the $\mathrm{L}_{9}\left(3^{4}\right)$ orthogonal array, the quantified results from fuzzy deduction for the MRR are determined and shown as Table 5.

Introducing the quantified results from fuzzy deduction as the Signal to Noise ratio $(\mathrm{S} / \mathrm{N})$ for MRR as larger-the-best expectation, the results of factor responses are calculated and listed in Table 6. The mean effects for $\mathrm{S} / \mathrm{N}$ ratios are then drawn by MINITAB 14 and shown as Fig. 3.

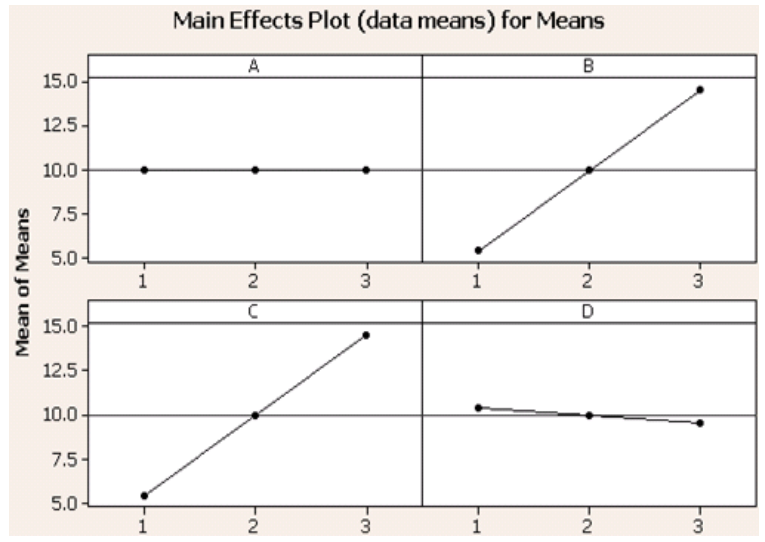

Fig. 3: Plot of main effects

Therefore, the optimum fuzzy deduction turning parameters are found to be A (high, medium, low), B (high) C (high) and D (low).

The finishing diameter turning operation of S45C $(\varphi 45 \times 205 \mathrm{~mm})$ work piece on an ECOCA-3807 CNC lathe is arranged for the simulated experiment. The TOSHIBA WTJNR2020K16 tool holder with MITSUBISHI NX2525 insert is utilized as the cutting tool. The four turning parameters (speed, cutting depth, feed rate and tool nose runoff) with three different levels (low, medium and high) (Table 7) are experimentally distinguished for the machining operation on the basis of $\mathrm{L}_{9}\left(3^{4}\right)$ orthogonal array. In Table 7, the three levels of speed, cutting depth and feed rate are identified from the machining handbook suggested by the tool manufacturer. The tool nose runoff is positioned by using different shims located under the tool holder and determined by measuring the tip after face turned the work piece. When the tool nose is set approximately $0.1 \mathrm{~mm}$ higher (lower) than the center of the work piece, it is regard as "High (Low)". When the tool nose is set within $\pm 0.03 \mathrm{~mm}$, it is considered as "Medium".

The MRR $\left(\mathrm{mm}^{3} \mathrm{~min}^{-1}\right)$ is calculated using MRR = $1000 \mathrm{fdV}$. Here; $\mathrm{f}\left(\mathrm{mm}\right.$ revolution $\left.{ }^{-1}\right)$ denotes the feed rate, $\mathrm{d}(\mathrm{mm})$ describes the cutting depth and $\mathrm{V}(\mathrm{m}$ $\mathrm{min}^{-1}$ ) presents the surface speed of the turning operation.

Table 3: Degree of membership for quality

\begin{tabular}{|c|c|c|c|c|c|c|c|c|c|c|c|c|c|c|c|c|c|c|c|c|c|}
\hline \multirow[b]{2}{*}{ Fuzzy item } & \multicolumn{21}{|c|}{ Interval } \\
\hline & 0 & 1 & 2 & 3 & 4 & 5 & 6 & 7 & 8 & 9 & 10 & 11 & 12 & 13 & 14 & 15 & 16 & 17 & 18 & 19 & 20 \\
\hline Excellent & 1 & 0.8 & 0.6 & 0.4 & 0.2 & 0.0 & 0.0 & 0.0 & 0.0 & 0.0 & 0 & 0.0 & 0.0 & 0.0 & 0.0 & 0 & 0.0 & 0.0 & 0.0 & 0.0 & 0 \\
\hline Good & 0 & 0.2 & 0.4 & 0.8 & 1.0 & 0.6 & 0.4 & 0.2 & 0.0 & 0.0 & 0 & 0.0 & 0.0 & 0.0 & 0.0 & 0 & 0.0 & 0.0 & 0.0 & 0.0 & 0 \\
\hline Fair & 0 & 0.0 & 0.0 & 0.0 & 0.0 & 0.0 & 0.2 & 0.4 & 0.6 & 0.8 & 1 & 0.8 & 0.6 & 0.4 & 0.2 & 0 & 0.0 & 0.0 & 0.0 & 0.0 & 0 \\
\hline Poor & 0 & 0.0 & 0.0 & 0.0 & 0.0 & 0.0 & 0.0 & 0.0 & 0.0 & 0.0 & 0 & 0.2 & 0.4 & 0.6 & 0.8 & 1 & 0.8 & 0.6 & 0.4 & 0.2 & 0 \\
\hline Worst & 0 & 0.0 & 0.0 & 0.0 & 0.0 & 0.0 & 0.0 & 0.0 & 0.0 & 0.0 & 0 & 0.0 & 0.0 & 0.0 & 0.0 & 0 & 0.2 & 0.4 & 0.6 & 0.8 & 1 \\
\hline
\end{tabular}


Table 4: Quantified results for linguistic results

\begin{tabular}{|c|c|c|c|c|c|}
\hline Scale & Excellent & Good & Fair & Poor & Worse \\
\hline Defuzzification & 1.33 & 5 & 10 & 15 & 18.67 \\
\hline \multicolumn{6}{|c|}{ Table 5: Fuzzy deduction results } \\
\hline \multicolumn{3}{|c|}{ Quality experiment } & & & MRR \\
\hline \multicolumn{3}{|c|}{1} & & & 1.33 \\
\hline \multicolumn{3}{|l|}{2} & & & 10.00 \\
\hline \multicolumn{3}{|l|}{3} & & & 18.67 \\
\hline \multicolumn{3}{|l|}{4} & & & 5.00 \\
\hline \multicolumn{3}{|l|}{5} & & & 15.00 \\
\hline \multicolumn{3}{|l|}{6} & & & 10.00 \\
\hline \multicolumn{3}{|l|}{7} & & & 10.00 \\
\hline \multicolumn{3}{|l|}{8} & & & 5.00 \\
\hline \multicolumn{3}{|l|}{9} & & & 15.00 \\
\hline
\end{tabular}

Table 6: Result of factor responses

\begin{tabular}{lrrrr}
\hline & Parameter & & \\
Level & A & B & C & D \\
\hline Low & 10 & 5.443 & 5.443 & 10.443 \\
Medium & 10 & 10.000 & 10.000 & 10.000 \\
High & 10 & 14.557 & 14.557 & 9.557 \\
Delta & 0 & 9.113 & 9.113 & 0.887 \\
Rank & 4 & 1.500 & 1.500 & 3.000 \\
\hline
\end{tabular}

Table 7: Parameters and levels

\begin{tabular}{lrrr}
\hline & Level & & \\
& - & & \\
Parameter & High & Medium & Low \\
\hline A: Speed $\left(\mathrm{m} \mathrm{min}^{-1}\right)$ & 250.0 & 200.00 & 150.0 \\
B: Cutting depth $(\mathrm{mm})$ & 3.0 & 2.00 & 1.0 \\
C: Feed rate $\left(\mathrm{mm} \mathrm{rev}^{-1}\right)$ & 0.4 & 0.30 & 0.2 \\
D: Tool nose runoff $(\mathrm{mm})$ & 0.1 & \pm 0.03 & -0.1 \\
\hline
\end{tabular}

Table 8: Confirmation results

\begin{tabular}{ll}
\hline & MRR \\
\hline Fuzzy deduction (A1B3C3D1) & $0.0225 \mathrm{~mm}^{3} \mathrm{~min}^{-1}$ \\
Fuzzy deduction (A2B3C3D1) & $0.03 \mathrm{~mm}^{3} \mathrm{~min}^{-1}$ \\
Fuzzy deduction (A3B3C3D1) & $0.0375 \mathrm{~mm}^{3} \mathrm{~min}^{-1}$ \\
Benchmark & $0.012 \mathrm{~mm}^{3} \mathrm{~min}^{-1}$ \\
\hline
\end{tabular}

\section{DISCUSSION}

To verify the applicability of the optimum result achieved by our proposed general optimization technique, the machining under both fuzzy Taguchi deduction optimization parameters and benchmark parameters; A (medium), B (medium), C (medium), D (medium), which are often introduced into the confirmation experiment in many of the studies (Tosun and Ozler, 2004; Liew and Ding, 2008) for comparison to the optimum parameters, are performed on the $\mathrm{CNC}$ lathe. The simulated machining results are concluded and listed in Table 8. From Table 8, it is observed that the MRR under fuzzy deduction parameters are significantly improved by $87.5,150.0$ and $212.5 \%$ from the benchmark parameters. It is shown that our proposed general deduction optimization technique can really advance the material removal rate.

\section{CONCLUSION}

In this study, the fuzzy Taguchi deduction was proposed and applied to achieve the optimum $\mathrm{CNC}$ finish turning parameters under the considerations of material removal rate. A confirmation simulation experiment of the optimum general deduction parameters was conducted to indicate the effectiveness of the proposed fuzzy Taguchi deduction optimization method. Through the confirmation test for the proposed method, the experimental results validate the potency that the MRR can be greatly advanced from the fuzzy Taguchi deduction optimization technique.

Parameter optimization is a hard-solving issue because of the interactions between parameters. This study not only proposes a fuzzy deduction general optimization approach using orthogonal array, but also contributes the satisfactory fuzzy linguistic technique for improving the productivity performances in CNC turning with profound insight. The competition of manufacturing industry will then be economically excited through the proposed development in this study.

\section{ACKNOWLEDGEMENT}

Financial support for this research was provided by the National Science Council Taiwan, ROC, under the contract of NSC97-2221-E-412-003.

\section{REFERENCES}

Anastasiou, K.S., 2002. Optimization of the aluminum die casting process based on the Taguchi method. Process. Inst. Mech. Eng. B. J. Eng. Manuf., 216: 969-977. DOI: 10.1243/09544050260174175

Chiang, Y.M. and H.H. Hsieh, 2009. The use of the Taguchi method with grey relational analysis to optimize the thin-film sputtering process with multiple quality characteristic in color filter manufacturing. Comput. Ind. Eng., 56: 648-661. DOI: $10.1016 /$ j.cie.2007.12.020

Davim, J.P. and C.A. Conceicao Antonio, 2001. Optimization of cutting conditions in machining of aluminum matrix composites using a numerical and experimental model. J. Mater. Process. Technol., 112: 78-82. DOI: 10.1016/S0924-0136(01)00551-9

Dhavlikar, M.N., M.S. Kulkarni and V. Mariappan, 2003. Combined Taguchi and dual response method for optimization of a centerless grinding operation. J. Mater. Process. Technol., 132: 90-94. DOI: $10.1016 / \mathrm{S} 0924-0136(02) 00271-6$ 
Edgar, G., W.B. Mona, V. Niels and H.E. Mark, 2008. Segmentation of electron tomographic data sets using fuzzy set theory principles. J. Struct. Biol., 162: 368-379. DOI: 10.1016/j.jsb.2008.01.017

Gungor, Z. and F. Arikan, 2007. Using fuzzy decision making system to improve quality-based investment. J. Intell. Manuf., 18: 197-207. DOI: 10.1007/s10845-007-0016-X

Haag, T., J. Herrmann and M. Hanss, 2010. Identification procedure for epistemic uncertainties using inverse fuzzy arithmetic. Mech. Syst. Signal Process., 24: 2021-2034. DOI: 10.1016/j.ymssp.2010.05.010

Huh, H., J.H. Heo and H.W. Lee, 2003. Optimization of a roller leveling process for Al7001T9 pipes with finite element analysis and Taguchi method. Int. J. Mach. Tool Manuf., 43: 345-350. DOI: 10.1016/S0890-6955(02)00269-9

Jianliang, G. and H. Rongdi, 2006. A united model of diametral error in slender bar turning with a follower rest. Int. J. Mach. Tools Manuf., 46: 1002-1012. DOI: 10.1016/j.ijmachtools.2005.07.042

Kim, S.J., K.S. Kim and H. Jang, 2003. Optimization of manufacturing parameters for a brake lining using Taguchi method. J. Mater. Process. Technol., 136: 202-208. DOI: 10.1016/S09240136(03)00159-6

Kopa, J., 2002. Optimal machining for achieving the desired surface roughness in fine turning of cold pre-formed steel workpiece. J. Mach. Tool Manuf., 42: 707-716. DOI: 10.1016/S0890-6955(01)00163-8

Lan, T.S. and M.Y. Wang, 2009. Competitive parameter optimization of multi-quality CNC turning. Int. J. Adv. Manuf. Technol., 41: 820-826. DOI: 10.1007/s00170-008-1495-4

Liew. W.Y.H. and X. Ding, 2008. Wear progression of carbide tool in low-speed end milling of stainless steel. Wear, 265: 155-166. DOI: 10.1016/j.wear.2007.09.003

Lin, W.S., 1998. The study of machining accuracy and tool wear reliability. Ph.D. Dissertation, National Central University, ROC.
Lin, W.S., B.Y. Lee and C.L. Wu, 2001. Modeling the surface roughness and cutting force for turning. J. Mater. Process. Technol., 108: 286-293. DOI: 10.1016/S0924-0136(00)00835-9

Meng, Q., J.A. Arsecularatne and P. Mathew, 2000. Calculation of optimum cutting conditions for turning operations using a machining theory. Int. J. Adv. Manuf. Technol., 40: 1709-1733. DOI: 10.1016/S0890-6955(00)00026-2

Palanikumar, K., 2008. Application of Taguchi and response surface methodologies for surface roughness in machining glass fiber reinforced plastics by PCD tooling. Int. J Adv. Manuf. Technol., 36: 19-27. DOI: 10.1007/s00170-0060811-0

Park, J.H., K.M. Yang and K.S. Kang, 2005. A quality function deployment methodology with signal and noise ratio for improvement of Wasserman's weights. Int. J. Adv. Manuf. Technol., 26: 631-637. DOI: $10.1007 / \mathrm{s} 00170-003-2036-9$

Ross, P.J., 1995. Taguchi Techniques for Quality Engineering. 2nd Edn., McGraw-Hill Publication, New York, ISBN: 10: 0070539588, pp: 329.

Tosun, N. and L. Ozler, 2004. Optimization for hot turning operations with multiple performance characteristics. Int. J. Adv. Manuf. Technol., 23: 777-782. DOI: 10.1007/s00170-003-1672-4

Venkata, R.R., 2006. Machinability evaluation of work materials using a combined multiple attribute decision-making method. Int. J. Adv. Manuf. Technol., 28: 221-227.

Wang, T.Y. and C.Y. Huang, 2007 Improving forecasting performance by employing the Taguchi method. Eur. J. Oper. Res., 176: 1052-1065. DOI: 10.1016/j.ejor.2005.08.020

Wu, F.C. and C.C. Chyu, 2002. A comparative study on Taguchi's SN ratio, minimizing MSD and variance for nominal-the-best characteristic experiment. Int. J. Adv. Manuf. Technol., 20: 655-659. DOI: 10.1007/s001700200203

Zadeh, L.A., 1965. Fuzzy sets. Inform. Control, 8: 338-353. DOI: 10.1016/S0019-9958(65)90241-X 